\title{
HEALTH PROBLEMS IN THE MANUFACTURE AND USE OF PLASTICS
}

\author{
BY \\ D. KENWIN HARRIS \\ From Imperial Chemical Industries Ltd., Plastics Division \\ (RECEIVED FOR PUBLICATION JUNE 8, 1953)
}

The increasing variety of plastic materials produced during the last few years is due mainly to the ability of the modern chemist to synthesize the chemical compounds from which plastics are made. The basis of most plastics today is the synthetic polymer and its introduction has made available many substances hitherto unknown in industry. Modern plastics are manufactured to serve specific purposes so that the synthetic polymers can no longer be regarded as substitutes for those found naturally as cellulose, rubber, and proteins. A wide range of materials can be made from them and so designed as to meet the actual properties required for any particular application.

In addition to the polymer, synthetic plastic materials contain varying amounts of other chemicals as catalysts, accelerators, stabilizers, hardeners, pigments, and so on, which are added to assist and regulate polymerization or to influence the properties of the final material, such as colour and flexibility. Most polymers are chemically inert and under ordinary circumstances the final plastic material should be comparatively harmless. It is admittedly difficult, however, in practice to effect complete polymerization and traces of free monomer or other chemicals may be present which can sometimes produce pathological conditions such as dermatitis.

Polymerized chemicals may be broadly divided into two groups, condensation and addition polymers. They may also be divided into thermoplastic or thermosetting types depending upon whether the polymer is softened or hardened by heating. The change that takes place on heating the thermosetting materials is irreversible.

\section{CONDENSATION POLYMER PLASTICS}

Condensation polymers are usually formed by the linkage of molecules with the elimination of water or some other compounds.

\section{Formaldehyde Products}

The thermosetting types in this group are those formed by the condensation of phenol, cresol, urea, or melamine with formaldehyde. In the manufacture and use of resins, glues, and moulding powders of this type free formaldehyde may be liberated under certain circumstances, the amount depending on such factors as the ratio of the ingredients, the degree of condensation, and the addition of other chemicals such as hexamethylenetetramine. For the sake of simplicity these products are discussed below in two separate sections depending upon whether they mainly affect the human body externally or internally.

Effects on the Skin.-Formaldehyde and hexamine are well known as primary irritants of the skin and mucous membranes and many factories handling resin glues have had cases of dermatitis at some time or another (Factory Department, 1943). Schwartz, Peck, and Dunn (1943) mention a factory of 800 employees where 600 cases of glue dermatitis occurred during the first six months of operation. In a small leather factory the incidence of dermatitis was highest $(28 \%)$ in the section where " notorious sensitisers such as formaldehyde, lacquer and Bismarck Brown were used " (Squire, Cruickshank, and Topley, 1950). It has been stated that the actual substance responsible for hexamine and formaldehyde dermatitis is formic acid (Schwartz, Tulipan, and Peck, 1947).

There is another factor that should be considered in assessing the predominant cause of dermatitis as the result of handling some of these products. In their usual commercial form, for example, these formaldehyde glues and resins will adhere to the skin and rapidly harden on contact with it, and Little (1950) considers this to be the primary cause of the more serious outbreaks of dermatitis from them.

Mayers and Silverburg (1936) stress the great variation in the length of time ranging from a few 
days to a period of years during which men were exposed to formaldehyde products before developing dermatitis. The same authors express doubts on the value of patch tests, and Silcock (1944) agrees with them, stating that they are of little or no practical value. Bamber (1950) asserts that patch tests are not for casual use and only an expert can make and interpret them. Thelwall Jones (1946) considers that their efficient use is an important aid to diagnosis but emphasizes the many errors that result when they are relied on for this purpose and when they are used to detect primary irritants. In view of these facts no patch tests were carried out on the cases described in this paper. In one investigation Schwartz (1945) determined by patch tests that workers were sensitive to resins containing phenol but to a lesser degree than to hexamine and formaldehyde.

The main products considered in this paper are moulding powders or aqueous glues and resins which are only partially polymerized by intention so that they do not harden on the skin and are easily removed by washing. This may account for the comparatively low percentage of cases of dermatitis in spite of the fact that the products may contain substantial quantities of free formaldehyde. The addition of a hardener to these aqueous glues and resins is generally necessary before they are used commercially as adhesives.

The moulding powders are manufactured by mixing resins with fillers such as paper or wood pulp and may also contain unreacted chemicals which are not, however, present in the finally moulded article. The latter is made by the application of heat and pressure to the moulding powder.

In a group of factories making these partially polymerized glues and moulding powders three clinical types of lesions have been distinguished. In the first the patient has usually worked only a few days or a week in the plant when he suddenly develops an acute eczematous reaction affecting the face, neck, scrotum, and less commonly the flexures. There is oedema, sometimes sufficient almost to close the eyelids, and often a papulovesicular eruption which may weep and crust. The hands and arms are generally unaffected. The condition appears quite suddenly during a working shift or a few hours later and is produced especially by fume although fine powder particles may also be responsible. It responds quickly to the removal of the patient from the plant and daily treatment in the ambulance room.

Case 1.-This man was a process worker, aged 45, who had been employed for five weeks on the disintegration of urea formaldehyde powder. Following symptoms of tingling of the face and lips he quickly developed an acute papulo-vesicular eczema of the whole face, neck, and elbow flexures. There was oedema of the eyelids and lips but it quickly subsided when the patient was removed from his job and attended the ambulance room daily for treatment.

The patient insisted on returning to the plant when he had completely recovered and after a few weeks he resumed shift work. Three months later the condition recurred in exactly the same places as were previously affected and on this occasion the man was removed permanently from the job.

Case 2.-This man, aged 61 , was employed as a carpenter and for two days before he reported to the medical department he had been repairing windows in the densification section of a urea formaldehyde plant. He also stated that he had not been in this plant for a month or so before this particular job. When seen in the ambulance room he had oedema of the eyelids and face which responded rapidly when he was removed from the plant and treated with a bland lotion.

After recovery this man was also very anxious to be permitted to work in all sections of the factory and after three or four months he was allowed to do this.

In the second type the eruption starts as a typical exogenous eczema affecting the interdigital areas, the backs of the hands, the fronts of the wrists, and forearms. Other parts that may especially be affected are those exposed to friction from clothing, e.g. the wrists, the ankles, the neck, and flexures. The palms of the hands are seldom affected but keratodermia and smooth, glossy finger tips with hyperidrosis is occasionally a feature similar to that seen in the hands of manual labourers. Sometimes there is softening of the finger nails with splitting and scaling but this is much more common with men who have been exposed for a period of years. This type of dermatitis may appear years after the man has worked without harm in contact with formaldehyde preparations and seems to depend upon the actual handling of formaldehyde products or contamination of the skin with syrups, resins, powders, etc.

Case 3.-The patient, aged 36, had worked for six months in the plant on the reaction vessels making urea formaldehyde syrups and had noticed a rash of the forearms for some time before he reported. On examination he had papulo-vesicular eczema of the backs of the fingers and the flexor surfaces of both forearms. Although the syrup is mixed mechanically he had occasionally to extract a sample for testing purposes and did not always wear gloves for this purpose. He was successfully treated in the ambulance room with daily dressings of a bland cream.

Several months later he had a recurrence of the skin condition and on this occasion he also developed a massive oedema of the face which appeared overnight. The hands now showed a more chronic scaly eczema 
of the fingers and dorsa which reacted very slowly to treatment although the oedema of the face subsided within a day or two. Shortly afterwards he took a fortnight's holiday when the condition cleared entirely.

The third type of lesion is one in which the eruption may combine the clinical features of the two types described above.

Case 4.-A maintenance fitter, aged 62, developed dermatitis after working on machines contaminated by urea formaldehyde dust. This affected only the hands and arms in the first place and he was removed from the job and given work as a storekeeper following which the condition healed. While in the stores he was one day inadvertently handed a number of valves contaminated with urea formaldehyde powder and within a few hours he had developed a sensitization eczema affecting the face, hands, forearms, axillae, scrotum, and groins. He was taken off work altogether and only slowly responded to treatment extending over a period of weeks. On his return to work he complained that he felt an immediate tingling of his eyes and face even when he entered the factory for a few moments as he did contrary to instructions on one or two occasions. He was finally given work as a commissionaire in a laboratory building far removed from the factory itself and he has had no further trouble during the last few years.

The problem of permanent alternative work for dermatitis cases presents difficulties, and Squire and others (1950) have rightly stressed that each individual case must be given serious consideration before a decision is made one way or the other. It has been found that most cases of dermatitis from formaldehyde occurring in this group of factories become sensitized to it so that they seem more liable to a skin eruption subsequently but a few develop an immunity or possibly take greater care on returning to their work. This is in agreement with Schwartz (1945) but contrary to his opinion urea formaldehyde resins seem to be as potent a cause of dermatitis as phenol formaldehyde preparations. This may be due to the fact that in the cases described by him the glues and resins were of that composition which rapidly hardened on contact with the skin.

In one small factory manufacturing urea and phenol formaldehyde resins, glues, and moulding powders the number of cases of dermatitis were comparatively few as can be seen in the accompanying table. This factory employed an average of between 150 and 250 men at any one time over a period of years but since the labour turnover was high many more individuals than the average number were exposed to risk during each year.

This table shows that the amount of time lost each year tends to diminish in spite of the marked increase in production. An interesting feature is the

\begin{tabular}{c|c|c|c|c}
\hline Year & $\begin{array}{c}\text { Production } \\
(1945=100)\end{array}$ & $\begin{array}{c}\text { Dermatitis } \\
\text { Cases }\end{array}$ & $\begin{array}{c}\text { Hours } \\
\text { Lost }\end{array}$ & $\begin{array}{c}\text { Lost Time } \\
\text { Cases }\end{array}$ \\
\hline 1945 & 100 & 9 & 1,238 & 1 \\
1946 & 150 & 10 & 1,292 & 6 \\
1947 & 194 & 11 & 80 & 1 \\
1948 & 260 & 9 & 208 & 4 \\
1949 & 370 & 16 & 96 & 2 \\
1950 & 447 & 15 & 39 & 2 \\
\hline
\end{tabular}

large percentage of time lost by a small number of men. Eighty per cent. of the total time lost was caused by five men (more than half of this was due to one man). Seventy-seven per cent. of the total number of cases of dermatitis lost no time and were successfully treated while continuing to workoccasionally at the same job. During the last two years (1949-1950) only four men lost time and between them accounted for less than $5 \%$ of the total time lost through dermatitis.

Effects on Absorption.-The acute effects of formaldehyde vapour on the eyes and respiratory passages are well known; they are frequently produced by vapour concentrations as low as 20 to 30 p.p.m. Lower concentrations may result in watering of the eyes, irritation of the throat and upper respiratory tract (Barnes and Speicher, 1942), but these symptoms often disappear after a short interval (10-30 minutes) as the worker gradually becomes accustomed to the vapour. The inhalation of high concentrations has been shown to produce pulmonary oedema and haemorrhage but the pungency of the vapour usually makes it impossible to remain in atmospheres contaminated to such an extent. The extensive literature on its toxicity is well summarized by the U.S. Public Health Service (1945), but in spite of the vast number of investigations which have been undertaken there is a notable lack of information and conformity of opinion on the possible chronic effects in man produced by the repeated absorption of small quantities over a long period of time.

Fischer (1905) asserts that the inhalation of the gas even in small quantities is followed by bronchitis and pneumonia but few other investigators agree with this statement. A case is quoted by Lile (1910) of a tuberculous patient who was kept in a room saturated with formaldehyde gas for several weeks, during which time the patient actually gained weight and his physical condition apparently improved. These effects are surprising even though the actual atmospheric concentration of formaldehyde in the room is not known. The term "saturated" conveys very little except that the concentration was presumably high. It is possible for men to work without embarrassment in atmospheres contaminated with formaldehyde to an 
extent that would immediately produce irritation of the eyes and upper respiratory tract of anyone who suddenly entered such a plant but such concentrations would amount to no more than a few parts per million.

McGuigan (1914) states that the result obtained by Lile is contrary to the experience of most investigators, and he suggests that strong concentrations or large doses of formaldehyde vapour will always produce some inflammatory reactions but these often pass unrecognized owing to the usually rapid and complete recovery. Yonkman, Lehman, Pfeiffer, and Chase (1941) described two men who daily consumed increasing quantities of formaldehyde in water over a period of several weeks until $200 \mathrm{mg}$. were being consumed each day. No significant changes were found in the blood, and urine tests were negative for free formaldehyde and albumin. Feeding rats with food containing formaldehyde confirmed this low toxicity.

In view of this uncertainty on the effects of absorbing formaldehyde it was decided to undertake an investigation on a group of men in one small factory. This factory was engaged mainly in making urea formaldehyde resins and powders and some phenol formaldehyde resin, each man having been employed for a minimum period of five years. Formaldehyde could usually be detected by smell in most parts of the plant but apart from occasional accidental spillings which might produce high local concentrations, repeated general atmospheric concentration tests revealed no more than 30 parts per million of formaldehyde. The latter concentration was found directly over an open mixer, and as a general rule the figures for most parts of the plant were below 10 p.p.m. which is the permissible concentration if conditions are to be regarded as satisfactory. All these men would presumably have repeatedly inhaled small concentrations of formaldehyde almost daily throughout the period of their employment.

The investigation consisted of a clinical examination, a chest radiograph, and a complete blood count in each case. The only figures given for the blood examination in Table 1 are those considered to be outside the normal limits. A white cell count of 5,000 to 10,000 per c.mm., colour indices, erythrocyte counts, and haemoglobin concentrations within the normal limits for men as described by Hutchison and Hunter (1949) are therefore omitted from the table.

In many instances each man had been employed on more than one job during his years of service and in a few cases men had spent some of the time away from exposure to formaldehyde. The majority however had spent most of their working time in a . formaldehyde plant.

Four of the men had developed dermatitis at some time or another but so mildly that it cleared within a few days with treatment in the ambulance room. No time was lost by any of the men from this condition.

Six of the blood counts showed a temporary reversal of the polymorphonuclear-lymphocyte ratio. When the counts were repeated a few weeks later the ratio had returned to normal in five cases.

Four of the men complained of mild dyspnoea on exertion. Of these No. 16 has hypertension with cardiac enlargement and albuminuria while No. 5 had suffered from asthma for several years. All other clinical abnormalities are summarized in the table.

\section{Polyamides}

Nylon is the generic name given to all synthetic fibre-forming polyamides. These are thermoplastic and are usually made by condensing a diamine with a dibasic acid and polymerizing the resultant salt by heat under pressure.

Since there are a large number of diamines and dibasic acids the number of possible polyamides or nylons is considerable. A wide variety of articles has been manufactured from nylon, for example, textiles, brushes, bearings, gears, cams and electrical components, to mention only a few. One variety (a condensation product of hexamethylene diamine with adipic acid) has been used to make surgical sutures which have been widely employed with apparently no ill effects. Haxton (1945) states that it causes a minimum of tissue irritation and its use as buried suture material has shown its superiority to catgut, silk, linen and cotton thread.

Another of the nylons has been used in the form of a film as an occlusive dressing, and experiments showed that it modified the bacterial flora of the skin beneath the dressing. Pathogenic organisms such as Staph. aureus disappeared within a few days and bacterial colonies were considerably reduced beneath the dressing in contrast to the adjoining skin where they persisted (Bull, Squire, and Topley, 1948). The advantages of these dressings have been shown by Schilling, Roberts, and Goodman, (1950) in the treatment of minor wounds in a controlled clinical trial.

Certain grades of commercial nylon may contain other chemicals besides the various polymers so that each nylon must be considered separately with regard to its toxicity or other properties.

\section{ADDITION POLYMER PLASTICS}

Addition polymers are of many types but they have in common their method of formation which is by 
TABLE 1

CLINICAL DATA OF 25 MEN EXPOSED TO FORMALDEHYDE VAPOUR

\begin{tabular}{|c|c|c|c|c|c|c|c|c|}
\hline No. & Age & $\begin{array}{l}\text { No. of } \\
\text { Years } \\
\text { Employed }\end{array}$ & $\begin{array}{l}\text { Wei } \\
\text { st. }\end{array}$ & & $\begin{array}{l}\text { Blood } \\
\text { Pressure }\end{array}$ & $\begin{array}{c}\text { Summary of } x \text {-Ray Report } \\
\text { of Chest }\end{array}$ & $\begin{array}{l}\text { Complete Blood } \\
\text { Count }\end{array}$ & Other Findings \\
\hline 1 & 49 & 13 & 10 & 5 & $140 / 80$ & Normal & Normal & Dermatitis (lasted six days-no \\
\hline 2 & 46 & 10 & 8 & 3 & $110 / 65$ & Normal & White cells 10,500 & - \\
\hline 3 & 49 & $5 \frac{1}{2}$ & 10 & 2 & $120 / 65$ & $\begin{array}{l}\text { Old healed focus right } \\
\text { upper zone }\end{array}$ & White cells 11,400 & - \\
\hline 4 & 50 & $6 \frac{1}{2}$ & 11 & 5 & $110 / 70$ & Normal & Normal & 一 \\
\hline 5 & 47 & $7 \frac{1}{2}$ & 10 & 2 & $120 / 70$ & $\begin{array}{l}\text { Suggestion of basal bronchi- } \\
\text { ectasis. Old healed focus } \\
\text { right upper zone. No } \\
\text { evidence of activity }\end{array}$ & White cells 13,900 & $\begin{array}{l}\text { Clinical chronic emphy sema. } \\
\text { Changed his job, left the factory } \\
\text { shortly after examination }\end{array}$ \\
\hline 6 & 51 & $6 \frac{1}{2}$ & 9 & 10 & $126 / 80$ & Normal & White cells 4,100 & - \\
\hline 7 & 43 & $7 \frac{1}{2}$ & 9 & 11 & $110 / 70$ & Normal & Normal & - \\
\hline 8 & 51 & 11 & 10 & $10 \frac{1}{2}$ & $120 / 80$ & Normal & Normal & - \\
\hline 9 & 45 & 18 & 7 & 13 & $145 / 90$ & Normal & Hb. $92 \%$ & - \\
\hline 10 & 45 & $10 \frac{1}{2}$ & 11 & 51 & $130 / 80$ & Normal & White cells 13,250 & - \\
\hline 11 & 35 & 5 & 11 & $3 \frac{1}{2}$ & $140 / 70$ & Normal & White cells 12,800 & - \\
\hline 12 & 40 & 8 & 10 & 5 & $145 / 90$ & Normal & Normal & - \\
\hline 13 & 24 & $9 \frac{1}{2}$ & 12 & $5 \frac{1}{2}$ & $120 / 70$ & Normal & Normal & - \\
\hline 14 & 57 & 6 & 7 & 123 & $120 / 65$ & $\begin{array}{l}\text { Old healed focus left upper } \\
\text { zone. No evidence of } \\
\text { activity }\end{array}$ & White cells 11,700 & $\begin{array}{l}\text { Dermatitis-no time lost. Chest } \\
\text { radiograph two years later } \\
\text { showed no change from his } \\
\text { previous report }\end{array}$ \\
\hline 15 & 36 & 9 & 7 & 11 & $120 / 70$ & Calcified hilar glands & Normal & 一 \\
\hline 16 & 61 & 7 & 10 & 13 & $160 / 115$ & $\begin{array}{l}\text { Cardiac enlargement-ven- } \\
\text { tricular hypertrophy. No } \\
\text { pulmonary disease }\end{array}$ & Normal & $\begin{array}{l}\text { Cardiac enlargement-confirmed } \\
\text { clinically. (Triple rhythm), } \\
\text { aortic } 2 \text { nd }+ \text {. Pulmonary bases } \\
\text { clear. Some evidence of hyper- } \\
\text { tensive retinitis. Urine, albu- } \\
\text { min }++\end{array}$ \\
\hline 17 & 59 & 6 & 8 & 8 & $140 / 80$ & Increased vascular shadows & White cells 14,900 & $\begin{array}{l}\text { "Arthritis", left elbow and right } \\
\text { knee }\end{array}$ \\
\hline 18 & 37 & $5 \frac{1}{2}$ & 10 & $2 \frac{1}{2}$ & $130 / 80$ & Normal & Normal & - \\
\hline 19 & 38 & 11 & 8 & $0 \frac{3}{4}$ & $120 / 70$ & Normal & White cells 4,500 & 一 \\
\hline 20 & 53 & 6 & 10 & $11 \frac{1}{2}$ & $150 / 85$ & $\begin{array}{l}\text { Cardiac enlargement con- } \\
\text { sistent with hypertension. } \\
\text { Increased vascular sha- } \\
\text { dows. No pulmonary } \\
\text { disease }\end{array}$ & White cells 11,800 & 一 \\
\hline 21 & 46 & $5 \frac{1}{2}$ & 13 & $10 \frac{1}{2}$ & $170 / 100$ & $\begin{array}{l}\text { Cardiac enlargement. Vas- } \\
\text { cular shadows increased. } \\
\text { No pulmonary disease }\end{array}$ & White cells 14,100 & 一 \\
\hline 22 & 60 & 13 & 9 & 6 & $180 / 75$ & $\begin{array}{l}\text { Old focus right apex. } \\
\text { Shadow left apex. } \\
\text { evidence of activity }\end{array}$ & $\begin{array}{l}\text { R. B.C. } 4,860,000 \text {. } \\
\text { Hb. } 88 \% \text {. White } \\
\text { cells } 10,000\end{array}$ & $\begin{array}{l}\text { Dermatitis mildly on two occa- } \\
\text { sions. No time lost. Chest } \\
\text { radiograph one year later-no } \\
\text { change from previous report }\end{array}$ \\
\hline 23 & 49 & 5 & 9 & 8 & $120 / 80$ & $\begin{array}{l}\text { Emphysema. Fibrosis both } \\
\text { apices and upper zones, } \\
\text { probably old infiltration. } \\
\text { No evidence of activity }\end{array}$ & Normal & $\begin{array}{l}\text { Mild dermatitis (no time lost). } \\
\text { Keratosis palmare }\end{array}$ \\
\hline 24 & 44 & 6 & 10 & $2 \frac{1}{2}$ & $120 / 80$ & Normal & Normal & 一 \\
\hline 25 & 37 & 8 & 9 & $10 t$ & $120 / 65$ & $\begin{array}{l}\text { Slight increased shadows } \\
\text { lower zones }\end{array}$ & Normal & - \\
\hline
\end{tabular}


the linkage of molecules containing a double bond. The effects of some of these polymers and their derivatives are described in this section.

\section{Polythene}

One of the simplest examples of this group is the thermoplastic material polythene (" alkathene") formed by the polymerization of the gas ethylene under high pressure. It is a long chain polymer containing several hundred $\mathrm{CH}_{2}$ units and the formula can roughly be represented thus $\left(-\mathrm{CH}_{2}-\mathrm{CH}_{2}\right.$ $-\mathrm{CH}_{2}-\mathrm{CH}_{2}-$ )n.

A brief history and a comprehensive description of the properties of this simplest synthetic plastic have been given by Swallow (1944). In pure form this polymer has been shown by experience to be remarkably innocuous having been used for many medical and surgical procedures involving close and prolonged contact with human and animal tissues (Farquhar and Lewis, 1948). In one notable instance it has been used with apparent success as a substitute for a portion of a diseased femur in a patient (Seddon and Scales, 1949). Although chemically inert it has apparently, under what must be admitted to be exceptional conditions, produced in one case some tissue reaction with giant cell formation and fibrosis, but implantation in the abdominal wall of a guinea-pig showed minimal reaction in this respect (Newman and Scales, 1951).

\section{Vinyl Chloride $\left(\mathrm{CH}_{2}=\mathrm{CHCl}\right)$}

The substitution of one chlorine for a hydrogen atom in ethylene results in an active gas known as vinyl chloride. For ease and safety in transport and handling vinyl chloride is contained in metal cylinders under pressure as a liquid. It is a mild narcotic and similar in its action to ethyl chloride (Fairhall, 1949). Concentrations in the atmosphere should not exceed 500 p.p.m. if working conditions are to be considered satisfactory. It boils at $-13.9^{\circ} \mathrm{C}$ and the liquid will act as a vesicant if it accidentally contacts the skin as can be seen in the following instance :

Case 5.-This man, aged 28 , had his hands accidentally sprayed with vinyl chloride. At the time the fingers felt numb and he stated that he had a feeling that his "thumb did not belong to him ". A little later he reported to the ambulance room by which time he had developed a marked erythema of the whole hand and some oedema of the fingers. On the dorsum of the right thumb there was a small second degree burn. The hands were dressed with a bland cream but the following day he had developed second degree burns of all the interdigital clefts of the right hand as well as a small second degree burn of the left index finger. With appropriate treatment the condition healed within two weeks.

\section{Polyvinyl Chloride}

Vinyl chloride can be polymerized to produce an inert material, polyvinyl chloride (" porvic", "geon"). No cases of dermatitis have been observed in its manufacture, processing or handling. A few cases, however, have been reported as the result of contact with the final plastic article which usually contains plasticizers, stabilizers, and other substances besides the polymer. The added chemicals in this instance are not primary skin irritants and there have been no skin lesions in this group of factories which could be directly attributed to them. Common examples are tricresyl phosphate, phthalates, chlorinated paraffin wax, lead carbonate, cadmium and calcium stearate, pigments, etc.

Two cases of dermatitis due to wearing garters, suspenders, and a wrist watch strap made from a plasticised copolymer of vinyl chloride and vinyl acetate have been reported by Zeisler (1940) but he adds that the percentage of such cases is very low in comparison with the large number of such plastic articles in use.

Plasticizers such as tricresyl phosphate and phthalates that are added to polyvinyl chloride increase its flexibility and it.should be appreciated that under certain circumstances these substances may " bloom" or " leach" out of the final plastic material. This may be a slow process during which time the plastic deteriorates and gradually becomes brittle. The toxicity of ortho-tricresyl phosphate is well established, and the subject has been fully reviewed by Hunter, Perry, and Evans (1944) who describe cases of poisoning due to its absorption. They state that 3 to $5 \mathrm{~g}$. of the material was a fatal dose to domestic fowls and that it can be absorbed through the skin.

Other chemicals may also be carried out in this " leaching " process. Lead carbonate, for example, is sometimes used as a stabilizer for polyvinyl chloride, and lead salts have been found experimentally in sufficient quantities to be detected by quantitative analysis in liquids left in contact with plastic tubing or vessels made of this material.

No cases of poisoning from these added substances have occurred in the factories mentioned in this paper.

There are fortunately less harmful chemicals that can be substituted for toxic plasticizers to produce a flexible material. The phthalates are a typical example since dimethyl and dibutyl phthalate have been used on the human skin as insect repellants (Anon, 1947). Some of the higher phthalates have been submitted to physiological tests with satisfactory results when they are administered by mouth, by inhalation or applied to the skin 
(Appendix a). Mallette and von Haam (1952) found that dioctyl phthalate administered intraperitoneally in comparatively large doses proved toxic to animals, but no delayed effect or permanent injury was noted in surviving animals.

\section{Tetrafluorethylene $\left(\mathrm{CF}_{2}=\mathrm{CF}_{2}\right)$}

The substitution of four fluorine for the hydrogen atoms of ethylene produces an unstable reactive gas known as tetrafluorethylene. This and its polymerized form have been discussed in a previous paper which describes the toxic effects of the polymer under certain exceptional conditions (Harris, 1951).

Methyl Methacrylate $\left(\mathrm{CH}_{2}: \mathrm{C}\left[\mathrm{CH}_{3}\right] \mathrm{COOCH}_{3}\right)$

Methyl methacrylate, B.P. $100^{\circ} \mathrm{C}$, is a colourless liquid with a sweetish, characteristic odour.

It is a mild irritant of the mucous membranes and in a few instances has been known to produce dermatitis. Spealman, Main, Haag, and Larson (1945) state that the instillation of three drops of this monomer into the eye of a rabbit produced immediate irritation with inflammation and oedema within a few hours. Complete recovery occurred after three days. On the skin it produced a very mild irritation which was fleeting in its effects. The writers also describe the toxicity of the monomer when administered to various animals subcutaneously, intraperitoneally, orally and by inhalation, and pathological changes were found in the livers and kidneys resembling the lesions produced by carbon tetrachloride. It is interesting to note that changes were found in the lungs due to its irritant action which in some instances were apparently reversible since healing subsequently occurred.

The same investigators submitted 50 volunteers to patch tests with the result that about one-third of the total developed a mild erythema in $\mathbf{4 8}$ hours. About $20 \%$ showed evidence of having developed a sensitivity to the monomer when tested ten days later. Polymerized methyl methacrylate similarly tested produced no effects.

The toxicity of the monomer when absorbed by experimental animals has been described by Deichman (1941) who also mentioned its irritant effect on the mucous membranes when inhaled. His experiments show that when absorbed in toxic quantities methyl methacrylate causes an increasing motor weakness, decreased respiration, dyspnoea, and loss of reflex activity; the animals finally died in coma as the result of respiratory failure.

The atmospheric concentration of methyl methacrylate should be maintained below 1,000 parts per million if working conditions are to be regarded as satisfactory. Its odour can be detected at far lower concentrations.

Cases of dermatitis due to handling this monomer are not common and the few that have occurred in the present group of factories have been of a mild nature, quickly responding to alternative work.

Case 6.-This man, aged 42, was engaged in making decorative plastic models. A great deal of the work was done with bare hands which involved fairly gross contamination with the liquid monomer and compositions containing it. He developed interdigital eczema of both hands but failed to report the condition to the ambulance room for a matter of four or five weeks. When first seen he had a dry, scaling eczema between the fingers of both hands and a papular erythema of the right forearm. This gradually cleared with local treatment and alternative work.

A few cases of dermatitis have been reported in dental mechanics using polymethacrylate and its monomer in the manufacture of dental prostheses. In such instances working conditions are often unsatisfactory so that it is very important to establish the real cause of the skin eruption and patch tests may be of value in these cases. Dental mechanics may be exposed to other irritants than methyl methacrylate and in some instances the use of abrasives (e.g. pumice powder) may have been the cause of the skin eruption.

\section{Polymethyl Methacrylate}

Under certain circumstances methyl methacrylate can be converted into a solid polymer that constitutes the basis of many commercial preparations known under the trade names " perspex", "lucite", " plexiglas", " diakon", " kallodent", etc. These commercial preparations vary in composition and may contain other chemicals besides the polymer. A brief history of the monomer together with a detailed description of the chemistry, the properties and some of the applications of the polymer have been given by Caress (1944).

The final polymer is like many others comparatively inert, e.g. it is used in the manufacture of contact lenses, artificial teeth, splints, and surgical instruments. Wilson (1946) has quoted 25 patients who had extrapleural prieumolyses by means of methyl methacrylate plombage. According to him the material fulfills all the essential criteria of an ideal for plombage, and ' it is non-irritating to the human body". For this operation the "methyl methacrylate was moulded into solid and hollow balls" so that it is obvious the writer means the polymerized form although he uses the term methyl methacrylate (the monomer) throughout his paper. 
It has been used to replace the head and part of the neck of the femur in operations by Judet and Judet (1950), and in cranial and reparative surgery Jeremiah (1950) used an implantation of polymethyl methacrylate which after three and a half years in position had apparently been successful.

Ridley (1952a) has described 22 successful cases of its implantation intra-ocularly to replace the lens. A later report (Ridley, 1952b) states that over 60 patients have had these lenses inserted at St. Thomas's Hospital and Moorfields Hospital.

Its effects at times however suggest that the polymer may liberate traces of free monomer or in some circumstances decompose on contact with the skin to form the monomer. In a sufficiently fine state, for instance, the powdered polymer can produce a dermatitis like that described above due to methyl methacrylate.

Case 7.-This man, aged 42 , had to sieve the polymer in powder form which he transferred from a drum to the sieve using a small hand scoop. His hands were constantly contaminated with the powder and eventually he developed a typical cheiropompholyx which responded very slowly to treatment. He was removed from work altogether for four weeks when the condition completely healed.

This has also occurred as the result of cutting sheets of the polymer with a band-saw when a spray of fine powder or "swarf" may be ejected over the man's hands and if the latter are hot or perspiring the skin is more likely to break down. Here again the original eruption is seen characteristically in the interdigital areas although the backs of the hands can be similarly affected.

Isolated cases have occurred of workers who complained of coughs, sore throats, and upper respiratory tract symptoms as the result of inhaling fine polymethacrylate powder or fume (Anon, 1946). This is not surprising in view of the mildly irritating effects on mucous membranes of the monomer and they can quite easily be prevented by improving the working conditions and particularly by providing local exhaust ventilation.

Methyl $\alpha$ chloracrylate $\left(\mathrm{CH}_{2}: \mathbf{C C l}: \mathrm{COOCH}_{3}\right)$

When the methyl radical in the $\alpha$ position in methyl methacrylate is replaced by chlorine the result as might be expected is a compound with markedly irritant properties.

This monomer can be polymerized to form materials similar to those described under polymethyl methacrylate. Methyl $\alpha$ chloracrylate (B.P. $126^{\circ} \mathrm{C}$ ) is a colourless liquid with an odour resembling methyl methacrylate. It is a powerful vesicant whose vapour will produce pulmonary oedema if inhaled in sufficient quantities. A drop or two on the unprotected skin will produce a blister in a day or two even though the affected part is thoroughly washed within a few seconds of the time of application. In this and other presects its properties conform with those described for this group of substances (vesicants) by Goldblatt (1945). The mechanism of vesication is discussed in some detail by the same author. A report on an investigation into its toxicity will be found in Appendix $b$.

Effect of the Liquid on the Skin.- In view of these facts it is not very surprising that specially designed plants and the institution of the most stringent precautions failed to prevent some accidents occurring to those engaged on work with this material, although no serious complications developed in any incident. Methyl chloracrylate penetrates rubber so that protective clothing of this material is inadequate. Some workers were burned in this way from accidental splashes of which they remained unaware because of their protective clothing until the earliest symptoms of smarting and tingling appeared a few hours later or blisters had occurred. An antidote was available for skin contamination in the form of a solution of potassium permanganate (half a dram to the pint).

Case 8.-This man, aged 27, was engaged in polymerizing methyl $\alpha$ chloracrylate monomer on a laboratory scale. He was wearing rubber gloves and stated positively that he did not make contact with the material with his bare hands. When he had finished the job he washed his hands with a solution of potassium permanganate. About three to four hours later he felt his hands tingling and later still noticed small pin point blisters between his fingers. The following day the vesicles had increased in number and the fingers felt irritable and hot. He reported to the ambulance room with several large blisters on the palms of both hands as well as a vesicular eruption of the fingers. These were treated as second degree burns and healed in due course (Fig. 1).

Case 9.-This man, aged 24, was employed making small quantities of methyl chloracrylate monomer in a laboratory. He was wearing protective clothing but removed his rubber boots on one occasion at work because his feet felt hot. Several hours later when he had returned home he noticed a blister on his right foot. The following day he reported to the ambulance room and was found to have a second degree burn of the distal half of the dorsum of the right foot. The blister was incised and tulle gras dressing applied. He remained away from work for a week at the end of which time the condition had practically healed.

An unusual case with some interesting features is worth describing in detail. It illustrates especially that substances which are normally regarded as 
harmless may become dangerous under comparatively trivial circumstances. It also stresses the importance of taking a full history and paying particular attention in this instance to the chemistry of the materials involved.

Case 10.-This laboratory worker, aged 24, was distilling methyl $\alpha \beta$ dichlorpropionate and spilled some of the liquid on to his left hand. He washed it off in the usual way and thought no more of it since previous experience had shown the chemical to be quite harmless. About three to four hours later he felt some irritation beneath the watch strap on his left wrist and thinking it was chafing his skin he transferred the watch to the other wrist. Two hours later he noticed irritation of the right wrist. The following morning when he reported to the ambulance room there were erythematous areas on both wrists. These were covered with tulle gras dressings.

The following day he was away from the district in spite of the fact that the areas had now blistered and he did not report to the ambulance room again until the next day. By this time he had large blisters on the anterior surfaces of both wrists (Fig. 2). The one on the left wrist measured 3 in. $\times 2$ in. $\times \frac{3}{4}$ in. They were incised, the fluid gently evacuated and the blistered skin allowed to collapse. Subsequent dressings with tulle gras produced rapid healing.

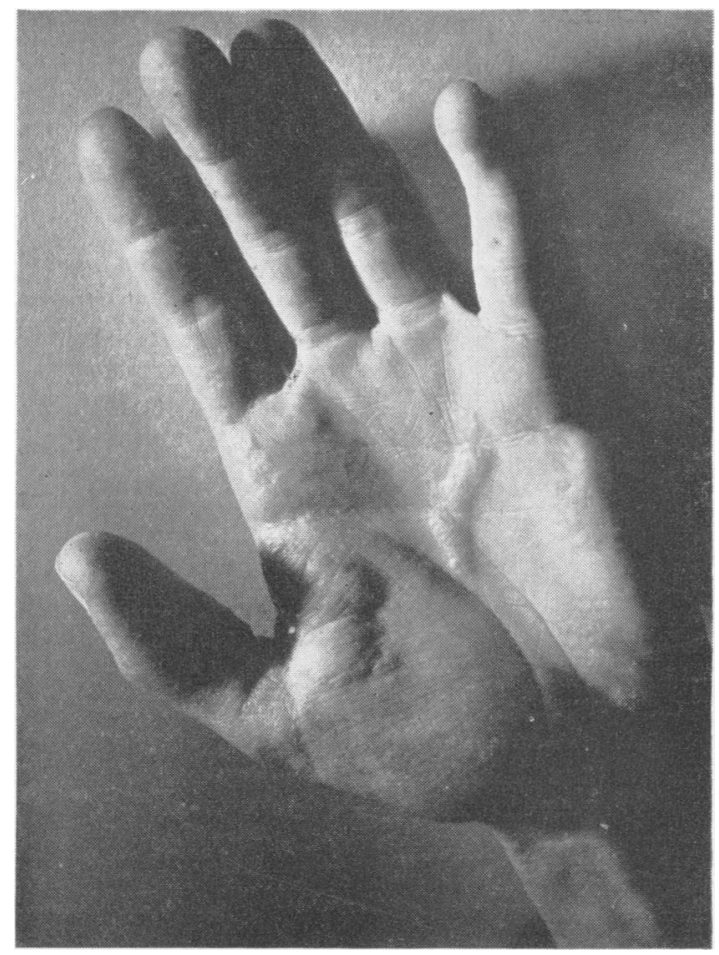

FiG. 1.-Vesicular eruption from exposure to methyl $\propto$ chloracrylate.

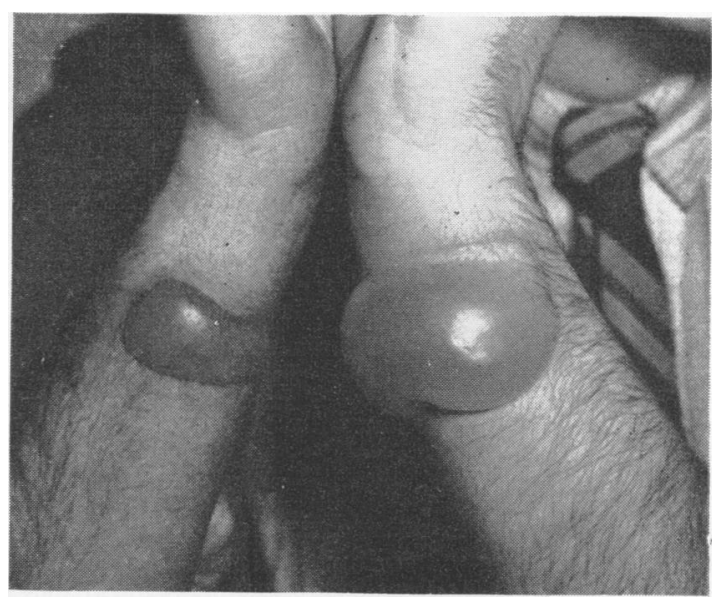

FIG. 2.-Large blisters on both wrists following exposure to methyl $\alpha \beta$ dichlorpropionate.

Methyl $\alpha \quad \beta$ dichlorpropionate readily loses a molecule of $\mathrm{HCl}$ to become the powerful vesicant methyl $\alpha$ chloracrylate.<smiles>COC(=O)/C=C\C(Cl)C(Cl)C(Cl)Cl</smiles>

This must have occurred on the skin beneath the wrist-watch strap through which the original substance had penetrated.

Effect of the Vapour on the Eyes.-The vapour of methyl chloracrylate is markedly irritant even in low concentrations (5 to 10 p.p.m.) so that symptoms of eye irritation with photophobia and lachrymation occur at an early stage. These symptoms may disappear without treatment and if the worker remains in contaminated atmospheres he is very likely to develop a severe conjunctivitis often after a latent interval of a few hours.

Case 11.-This man, aged 25, was employed in a laboratory where a bottle containing methyl $\alpha$ chloracrylate was accidentally broken on the floor. The laboratory was cleared but the patient proceeded to mop up the liquid with the assistance of one other colleague. He stated that afterwards he washed his hands thoroughly and had his eyes irrigated before continuing to work in the vicinity of the accident. Later that evening he developed the typical eye symptoms described above and the following morning he telephoned the medical department to state that he could not open his eyelids. $\mathrm{He}$ was brought to the ambulance room and on examination was found to have a severe bilateral conjunctivitis with oedema of the eyelids and intense blepharospasm. Following prolonged irrigation which was continued in the ambulance he was transferred to hospital where he 
remained as an in-patient for four days. A report from the ophthalmologist confirmed the findings and stated that both corneas were clear and unaffected. During the first day in hospital irrigation was continued and penicillin drops were inserted into the eyes. Within a few days the condition had completely resolved. This patient illustrated the typical effects of the vapour on the unprotected eyes.

This condition can be prevented in almost every case if the eyes are irrigated as soon as the first symptoms manifest themselves and the practical value of such prophylactic treatment has been shown by the development of eye signs in those who have neglected it. The composition of the fluid used matters far less than the speed, thoroughness and length of time of the actual irrigation. Ridley (1948) recommends $0.65 \%$ sodium chloride $(\mathrm{NaC} 1)$ in distilled water as the most suitable fluid for use as an eye lotion, and asserts that the practice of using " isotonic" solutions is unsound.

Several patients reported to the ambulance room from time to time with mild ophthalmic symptoms while working with methyl chloracrylate over a period of many months. Prophylactic irrigation of the eyes was frequently undertaken and this was either successful in every instance or possibly some of the patients were sufficiently apprehensive to seek this treatment when no exposure to fume had occurred.

Effect of the Liquid on the Eyes.-Splashes of the neat liquid into the eyes occurred on one occasion only. This accident involved two laboratory workers who were sprayed with methyl chloracrylate suddenly released from a flask under pressure when the fume cupboard door was open. These men were not wearing protective glasses with which they were issued.

Case 12.-This patient, aged 25 , immediately washed his face under a nearby tap and his eyes were irrigated on the spot by a first aid worker. When seen in the ambulance room he had a bilateral conjunctivitis with first degree burns of the face and neck. Following prolonged irrigation and the instillation subsequently of sulphacetamide drops he was sent to hospital. In spite of repeated irrigation during the next few hours and subsequent treatment under the care of an ophthalmologist, the following day he had marked oedema of both eyelids with intense blepharospasm. The lids could be separated only with difficulty and the conjunctivitis persisted. A few days later he had developed a small corneal ulcer of the right eye. This gradually healed while he was in hospital. He returned to work after about a fortnight's absence and continued to have treatment for the right eye for another week or so until the condition had completely resolved.
Case 13.-This youth, aged 17, was assisting the previous patient and was similarly sprayed in the face with the vesicant. He ran to the nearest ambulance room which he reached within a minute or so. On examination he had an acute bilateral conjunctivitis, the right eye being the more obviously inflamed. The eyes were irrigated for a total of about two hours and he was susbequently detained in the ambulance room for a much longer period. At the end of that time the eye seemed to have cleared and he had no symptoms so that he was allowed to go home. Some hours later, however, the eyes became painful and he was admitted to a hospital in the early hours of the morning. Later in the day he had developed acute bilateral conjunctivitis with oedema and spasm of the eyelids. He responded fairly rapidly to treatment and was back at work within a week. Incidentally this patient had a small second degree burn of the abdominal wall which passed unnoticed until he was examined in hospital since it produced no symptoms and the patient was quite unaware of the fact that he had been contaminated in that region.

Effect of Chronic Exposure to the Vapour.-There was some doubt whether chronic or repeated exposure to small doses might have affected the eyes of workers and it was therefore decided to examine a group of workers after they had been engaged on the work for some months. Thirty-four workers were submitted for examination by an ophthalmologist whose report is summarized below. The men were engaged on a large semi-technical plant manufacturing methyl chloracrylate monomer. The patients were divided into three groups :

\section{Group One : Without history of symptoms}

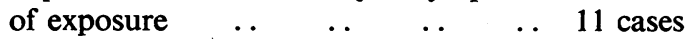

Group Two: With history of mild symptoms of exposure .. $\quad$.. $\quad$. 15 cases

Group Three : With history of symptoms of exposure severe enough to last 24

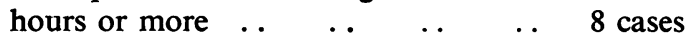

The ophthalmologist reported that no patient complained of symptoms at the time of the examination and there was no indication of any abnormal findings that could be attributed to the vesicant.

An additional 18 workers employed on a plant manufacturing the material on a production scale were also examined. The report stated that the only constant pathological finding was a superficial punctate keratitis in five patients. In no case was this more than slight and no treatment was recommended.

No respiratory symptoms occurred in any of the men involved in the work which suggests that atmospheric concentrations were low or that respirators were worn at appropriate times and places according to instructions. 

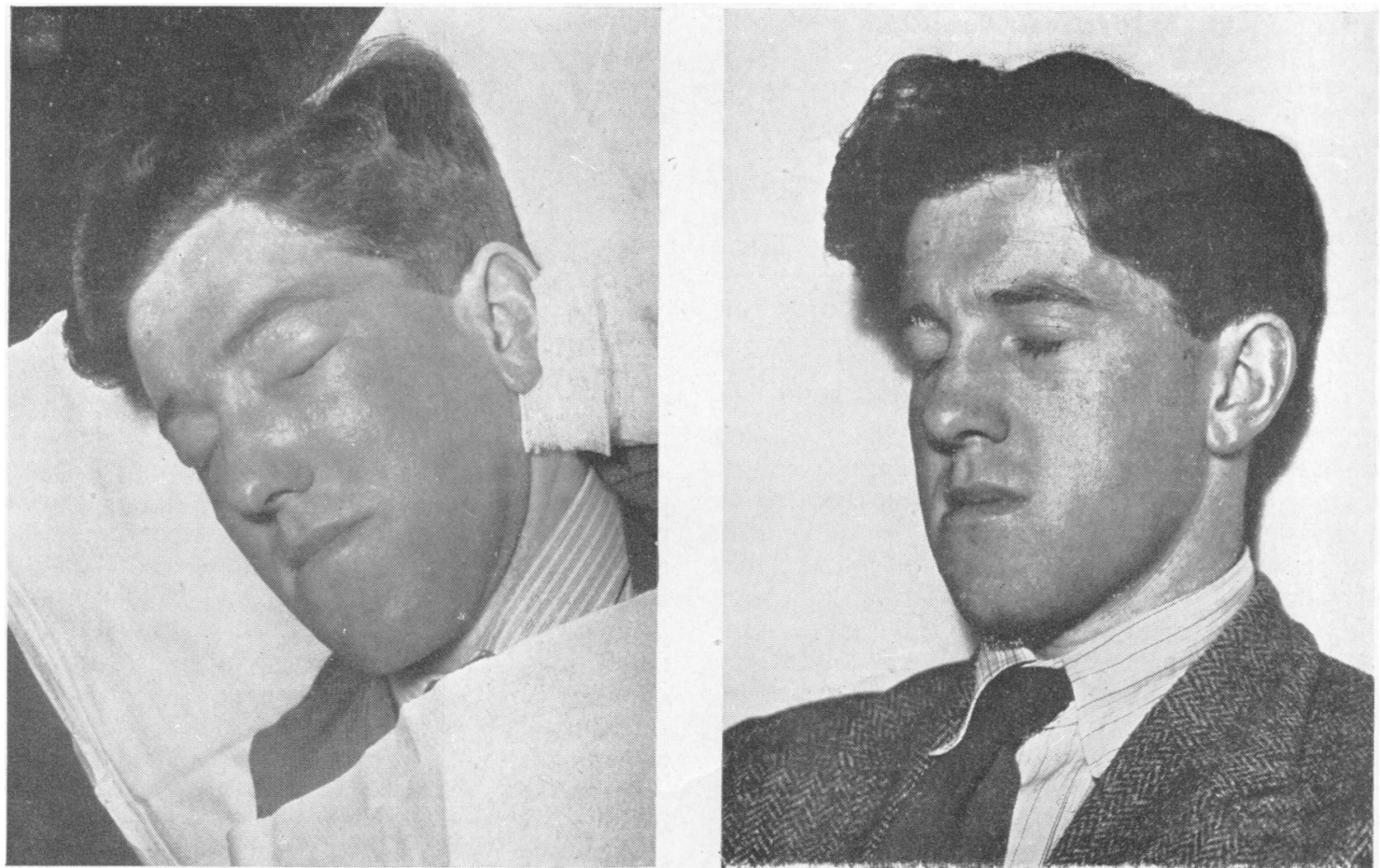

FIG. 3.-Facial oedema after the patient was splashed with chloracrylic acid. His normal features are shown for comparison.

\section{Polymethyl Chloracrylate}

As has been stated above methyl chloracrylate can be polymerized under certain circumstances to produce a material resembling "perspex". The presence of free monomer or decomposition products under particular conditions is suggested by the fact that machining the polymer on a lathe has given off the typical odour of the monomer and in one or two cases has produced eye symptoms. Local exhaust ventilation is sufficient to remove this hazard.

\section{Chloracrylic Acid}

A substance resembling methyl chloracrylate in its properties is $\alpha$ chloracrylic acid, and experimental evidence of its effects is given in Appendix $c$.

Case 14.-This man, aged 22, was employed in the laboratory esterifying ethylene glycol with chloracrylic acid when the contents of the flask suddenly splashed into his face. He immediately irrigated himself with water and subseqently with a dilute solution of potassium permanganate before reporting to the ambulance room. On examination he was found to have first degree burns of the face and neck with a mild conjunctivitis of the right eye. Prolonged irrigation of the eye and the application of a bland cream to the face seemed to produce a considerable improvement but by the next day the patient's face had become oedematous (Fig. 3). He also had second degree burns of the interdigital areas of the left hand and on both forearms. The right eye was not inflamed but the cornea showed a central pin head opacity and he was admitted to hospital for further treatment. His condition improved sufficiently rapidly for him to be discharged within a few days. A fortnight after the accident he was seen by an ophthalmologist who reported as follows :

"The cornea shows a near central pin head leucoma which has scarred the anterior epithelium and Bowmans membrane only. It has healed. Near it there are seven or eight minute staining specks on the surface of the anterior epithelium. This will heal without scarring."

On his recommendation the patient continued to have treatment in the form of sulphacetamide drops three times daily for a further brief period. The burns on the hand and forearms were dressed daily until they had healed.

The illustration of this patient's face might well represent the acute effects of formaldehyde vapour with the possible exception that in the latter condition the blisters tend to be smaller and more like eczematous vesicles.

\section{Laminated Plastics}

These are plastic materials made by impregnating layers of fabric or paper with resins which are subsequently polymerized by heat and pressure. 
Phenol formaldehyde resins have been extensively used for this purpose but more recently new laminates (" marco", " nuron", "laminac") have been made employing far lower pressures than those previously used in manufacture.

The polymers that result from the manufacture of these low pressure laminates are of the crosslinking type having thermosetting properties. Their composition is somewhat involved but a brief description of the chemical and general properties of one of them together with its applications has been given by Burness, Hammond, and Williams (1946).

The actual impregnation of the filler with the resin may be undertaken by very primitive methods, sometimes only the bare hands being used for the purpose. Since the resin is usually mixed with the monomer before application it is not very surprising that cases of dermatitis occur as a result. In some cases dermatitis may be caused by the fabric itself, as for example when woven glass fibre cloth may be used for the purpose (Fairhall, 1949). The resulting skin condition is almost invariably a typical occupational dermatitis affecting the interdigital areas, backs of the hands and wrists, and the arms. It can be prevented by mechanising the process or less satisfactorily by providing the operators with suitable protective clothing.

\section{Discussion}

So much has been written about occupational dermatitis that only a very brief reference can be justified here. Instructive accounts of the subject have been given by Squire and others (1950) and by Thelwall Jones (1946), and the preventive measures to be taken in the case of that due to formaldehyde products have been described by the Factory Department (1943). In the factories mentioned in this paper the use of sulphonated oils as cleansers has been found invaluable and they have in fact almost completely replaced the use of soap, which has the disadvantage of rendering the skin unnaturally dry (Horner, 1950). For the same reason they have been found preferable to the soap-woodflour mixture recommended by Cruickshank (1948).

The inefficiency of the usual protective clothing against some chemicals is shown by the effects of methyl chloracrylate on workers wearing rubber boots and gloves and a good example is provided by the illustration of the hand of the laboratory worker (Case No. 8) in Fig. 1.

The compositions of the local applications mentioned in the treatment of the cases of occupational dermatitis described above have been deliberately omitted since this is felt to be a matter of individual choice. Ingram (1948) has stressed the importance of using only simple or tried remedies and suggests suitable applications for common skin conditions. Wigley and Fox (1950) provide a list of " favourite prescriptions" for skin diseases with indications for their appropriate use; and finally a useful account of the properties of some of the new emulsifying bases and other pharmaceutical aspects of local applications has been given by Payne (1950).

The nature of the hazard and the reasons for the investigation into the possible effects of repeatedly absorbing small quantities of formaldehyde were clearly explained to the radiologist and haematologist. They were of the opinion that there was nothing abnormal in this respect that could be attributed to the men's occupation, and the final results shown in the table seemed to indicate that there is no definite evidence of ill health which can confidently be associated with exposure to formaldehyde. In nine instances the men had lost weight since they had begun the job several years previously and two cases suffering from dyspnoea apparently developed this while working in the plants but one or more of several factors may have been responsible.

Most polymers are chemically inert and normally produce no pathological effects. They may however contain traces of free monomer which is often a highly active chemical substance capable of being an irritant like formaldehyde, a narcotic such as vinyl chloride, or a vesicant in the case of methyl chloracrylate. The monomer can be liberated from the polymer under certain conditions as, for example, during the machining of polymethyl methacrylate sheet when the fine powder can produce irritant effects like the monomer.

In addition plastic materials may contain other chemicals known to be toxic such as caustic soda (catalyst), tricresyl phosphate (plasticizer), lead carbonate (stabilizer) or cadmium compounds (pigment), and it is possible for those to bloom or leach out of the material. These chemicals can also be extracted under certain conditions by subjecting the plastic to a solvent such as an acid or an alkali.

Lastly some polymers under unusual conditions give rise to decomposition products which may have toxic effects ; an example of this is the fever produced by inhaling the fume of polytetrafluorethylene which has been heated to an abnormally high temperature (over $300^{\circ} \mathrm{C}$.).

These facts, together with the increasing use of plastic materials for medical and surgical purposes or in connexion with foodstuffs, make it essential 
for their toxicity to be given careful consideration. Some of their uses in surgery have already been described but a few examples are given below of the way in which they may come into contact with food and drink. Plastics for this purpose may be used in the form of (a) cups, beakers, plates, trays, bowls and other utensils; $(b)$ tubes for conveying consumable liquids, e.g. water, beer, etc.; (c) films for wrapping ; (d) linings for food containers, refrigerators, conveyor belts, and machines used in the manufacture of food.

Plastics used for the above purposes therefore should ideally contain no toxic substance of any kind although this may sometimes be difficult to ensure in practice. In all cases of doubt it is essential that the plastic and its ingredients should be subjected to most rigid physical, chemical, and physiological tests to ensure the absence of toxicity in applications of this kind.

\section{SUMMARY}

Synthetic plastic materials are made from polymerized chemicals with the addition of various other compounds.

Polymers can be divided into condensation and addition, or thermoplastic and thermosetting types.

The condensation polymers are typically represented by a group of formaldehyde products. The effects of formaldehyde on the skin and after absorption are discussed. Clinical examples and the incidence of dermatitis in one small factory are quoted. The result of an investigation on workers making formaldehyde products is described to support the contention that formaldehyde has little or no chronic effects when repeatedly absorbed in small quantities.

The nylon polymers are briefly mentioned.

The pathological effects of some addition polymers, their monomers and substances associated with their manufacture are discussed, including polythene, polyvinyl chloride, polymethacrylate, and polymethyl chloracrylate.

A brief reference is made to laminated plastics.

The importance of a full investigation of plastic materials likely to be used for certain purposes is stressed.

I am grateful to Dr. R. G. Heyes for his assistance especially on the chemistry of the polymers; to Dr.
M. W. Goldblatt for toxicological reports ; to Dr. J. W. Rammell and Dr. J. S. Gourlay for their ophthalmic reports ; to Dr. C. H. Hilliard and Dr. V. Magee for their respective opinions on the results of the chest radiographs and blood examinations in the investigation on formaldehyde workers.

\section{REFERENCES}

Anon (1946). "Toxicity of Plexiglass." J. Amer. med. Ass., 131, 1103, Queries and Minor Notes.

-1947). "Any Questions?". Brit. med. J., 1, 551.

Bamber, G. (1950). Practitioner, 164, 385. J. industr. Hyg., 24, 10. Bull, J. P., Squire, J. R., and Topley, E. (1948). Lancet, 2,213 . Burness, A., Hammond, R., and Williams, E. G. (1946). Brit. Plast., 18, 274A.

Caress, A. (1944). Endeavour, 3, 156.

Cruickshank, C. N. D. (1948). British Journal of Industrial Medicine, $5,204$.

Deichmann, W. (1941). J. industr. Hyg., 23, 343.

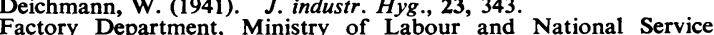
(1943). Memorandum on the Prevention of Industrial Dermatitis. Form 331, H.M.S.O.

Fairhall, L. T. (1949). Industrial Toxicology. Williams and Wilkins, Baltimore.

Farquhar, J. W., and Lewis, I. C. (1948). Lancet, 2, 244.

Fischer, M. H. (1905). J. exp. Med., 6, 487.

Goldblatt, M. W. (1945). British Journal of Industrial Medicine, 2,183 .

Harris, D. K. (1951). Lancet, $2,1008$.

Haxton, H. (1945). Brit. med. J., 1, 12.

Haxton, H. (1945). $\quad$ Brit. med. J., 1, 12.
Horner, S. (1950). Practitioner, 164, 234.

Horner, S. (1950). Practitioner, 164, 234.
Hunter, D., Perry, K. M. A., and Evans, R. B. (1944). British Journal of Industrial Medicine, 1, 227.

Hutchison, R., and Hunter, D. (1949). Clinical Methods, 12th ed. Cassell,'London.

Ingram, J. T.'(1948). Brit. med. J., 2, 187

Jeremiah, B. S. (1950). Plast. reconstr. Surg., 5, 252.

Jones, A. Thelwall (1946). British Journal of Industrial Medicine, 3, 83.

Judet, J., and Judet, R. (1950). J. Bone Jt Surg., 32B, 166.

Lile, S. (1910). J. Amer. med. Ass., 54, 554.

Lile, S. (1910). (1950). Amer. med. Ass., 54, 554.

Mallette, F. S., and Haam, E. von (1952). Arch. industr. Hyg., 6, 231 .

Mayers, M. R., and Silverburg, M. (1936). Industr. Bull., N.Y., $15,324$.

McGuigan, H. (1914). J. Amer. med. Ass., 62, 984.

Newman, P. H., and Scales, J. T. (1951). J. Bone Jt Surg., 33B, 392.

Payne, M. H., (1950). In Modern Practice in Dermatology, edited G. B. Mitchell-Heggs, p. 777. Butterworth, London.

Ridley, F. (1948). Trans. ophthal. Soc., U.K., 68, 301.

Ridley, H. (1952a). Lancet, 1, 118.

Schilling, R. S. F., Roberts, M., and Goodman, N. (1950). Lancet, 1,293 .

Schwartz, L. (1945). J. invest. Derm., 6, 239.

, Peck, S. M., and Dunn, J. E. (1943). U.S. Publ. Hlth Rep., 58, 899..

Tulipan, L., and Peck, S. M. (1947). Occupational Diseases of the Skin, 2nd ed. Kimpton, London.

Seddon, H. J., and Scales, J. T. (1949). Lancet, 2, 795.

Silcock, F. A. E. (1944). Brit. med. J., 2, 830

Spealman, C. R., Main, R. J., Haag, H. B., and Larson P. S. (1945). Industr. Med. 14, 292.,

Squire, J. R., Cruickshank, C. N. D., and Topley, E. (1950). Brit. med. Bull., 7, 28.

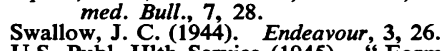

U.S. Publ. Hith Service (1945). " Formaldehyde-Its Toxicity and Potential Dangers." P.H. Rep. Supplement No. 181.

Wigley, J. E. M., and Fox, P. B. (1950). Practitioner, 165, 33.

Wilson, D. A. (1946). Surg. Clin. N. Amer., 26, 1060.

Yonkman, F. F., Lehman, A. J., Pfeiffer, C. C., and Chase, H. F. (1941). J. Pharmacol., 72, 46.

Zeisler, E. P. (1940). J. Amer. med. Ass., 114, 2540.

\section{A P P E N D I X}

The following toxicological data were obtained from experiments carried out at the Industrial Hygiene Research Laboratories of Imperial Chemical Industries Limited.

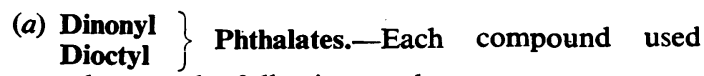
separately gave the following results :-

Oral Administration.-No ill effects observed in 
animals receiving doses by mouth up to $2.0 \mathrm{ml} . / \mathrm{kg}$. $(1.97 \mathrm{~g} . / \mathrm{kg}$.).

Inhalation.-No ill effects observed in rats exposed to air saturated with the vapour of the compound at $18^{\circ} \mathrm{C}$. and $28^{\circ} \mathrm{C}$. for 12 successive six-hour periods.

Skin Application.-The shaved rat skin remained normal after 10 applications (two applications of the neat material each day for five days). No ill effects were observed when it was applied to the skin of the human forearm twice daily for five days.

(b) Methyl Alpha Chloracrylate.-The toxicity is as follows :-

200 parts per million killed six rats after five hours' exposure.

100 parts per million killed six rats after six hours' exposure.

50 parts per million killed six rats after nine hours' exposure.

25 parts per million killed six rats after three six-hour exposures.

10 parts per million killed six rats after 30 to 84 hours' exposure.

Experiments with the vapour have shown that it is a highly toxic compound. Concentrations in air from 200 parts per million down to 10 parts per million caused death in rats from respiratory disorders after varying times of exposure.

Further experiments were carried out by human volunteers with the following results :

$0.025 \% v / v(250$ p.p.m.)-Immediate slight burning sensation in the eyes, followed by lachrymation, slight headache. Feeling of "tightness" over the eyes one hour later (total exposure 10 seconds).

$0.005 \% v / v(50$ p.p.m).-Lachrymation after about 10 seconds.

$0.001 \% v / v(10$ p.p.m.).-Very slight irritation of the eyes after 20 seconds.

$0.0005 \% v / v(5$ p.p.m.).-Very slight irritation of the eyes after 20 seconds.

These reactions were observed in three volunteers and were identical except that one volunteer did not experience headache at the concentration of 250 p.p.m.

It will be noted that all exposures were of short duration and that no difference was observed between 10 and 5 p.p.m. This may be different for longer exposure. In addition owing to previous experiments with rats showing the effects of 10 p.p.m. on the lungs, the volunteers did not inhale the vapours.

Effects on Human Skin.-Two drops of the neat material were applied to the inside skin of forearm. Burning sensation in 10 seconds. Quite painful after 20 seconds. Immediately washed off, washing kept up for five minutes. Slight erythema of treated area about size of a shilling. No pain. Twenty-four hours, painful to touch. Treated area, no increase in size. "Angry" red with pale centre (blistering). Forty-eight hours, definite blister, no pain and erythema much decreased. No treatment was applied but the area was kept clean.

(c) Alpha Chloracrylic Acid.-The acid, 5\% w/v in water attacks the skin and eyes and can severely damage the latter. The acid neutralized with caustic soda $(\mathrm{NaOH})$ to give a $5 \%$ sodium chloracrylate solution had no effect on rabbits' eyes and human skin.

Effects on Human Skin.-Of a $5 \% \mathrm{w} / \mathrm{v}$ aqueous solution of the acid, $0.5 \mathrm{ml}$., applied to human skin and allowed to dry caused a mild burning sensation and slight erythema after six minutes. The area was then washed with cold water. One hour later the erythema had increased and after two hours the treated area was very red and sensitive to touch. After 12 hours there was very little change, but after 24 hours the erythema was much reduced. No pain or sensitivity was present. After three days the skin was quite normal.

Rabbits' Eyes.-Two drops of the above solution placed in the conjunctival sac of a rabbit's eye caused immediate intense irritation. The animal kept its eye closed for about five minutes. When opened the eyelids were seen to be injected and after one hour they were oedematous. After two hours a whitish discharge appeared at the anterior corner of the eye. The pupil had contracted to about a third of normal size. Eyelids sealed with exudate. Twenty-four hours, no change. Forty-eight hours, no change. Seventy-two hours, the eye was half open and the oedema was somewhat lessened. The pupil was now about half size and reacted to light. Recovery was slow but no treatment had been applied.

Four drops of $5 \%$ sodium chloracrylate (aqueous acid solution neutralized with $\mathrm{NaOH}$ ) (two at one-hour intervals) had no effects on rabbit's eyes; $0.5 \mathrm{ml}$. applied to human skin (two at two-hour intervals) had no effect on human skin. 